\title{
Acute Respiratory Distress Due to Massive Lung Metastasis from Uterine Leiomyosarcoma as a Main Clinical Feature
}

\author{
Anna Sumigama ${ }^{1}$, Tsuneko Ikeda ${ }^{2}$, Satoshi Ichigo ${ }^{1}$, Hiroshi Takagi ${ }^{1}$, Kazutoshi Matsunami ${ }^{1}$, Ichiro \\ Kawabata $^{1}$ and Atsushi Imai ${ }^{1 *}$ \\ ${ }^{1}$ Departments of Obstetrics and Gynecology, Japan \\ ${ }^{2}$ Department of Pathology, Matsunami General Hospital, Japan
}

*Corresponding author: Atsushi Imai MD. PhD, Department of Obstetrics and Gynecology, Matsunami General Hospital, Japan

\begin{tabular}{|c|}
\hline ARTICLE INFO \\
\hline Received: 慧 February 12, 2020 \\
\hline Published: 幽 February 19, 2020 \\
\hline
\end{tabular}

Citation: Anna Sumigama, Tsuneko Ikeda, Satoshi Ichigo, Hiroshi Takagi, Kazutoshi Matsunami, Ichiro Kawabata, Atsushi Imai. Acute Respiratory Distress Due to Massive Lung Metastasis from Uterine Leiomyosarcoma as a Main Clinical Feature. Biomed J Sci \& Tech Res 25(5)-2020. BJSTR. MS.ID.004250.

\begin{abstract}
A 47-year-old woman with uterine leiomyosarcoma and acutely progressive respiratory distress is presented. She had been pointed out a $20 \mathrm{~cm}$-sized uterine tumor highly suspicious for 'leiomyoma' 5 years ago, but not undergone a hysterectomy. Sudden onset of respiratory distress due to a giant lung lesion led to emergency thoracotomy. Entire removal of lung lesion induced a rapid and favorable course, followed by the hysterectomy and bilateral salpingo-oophorectomy 5 months after the thoracotomy. Both of the lung lesion and uterine mass were considered a low-grade leiomyosarcoma. Base on the past medical history and histological similarity, she was diagnosed with uterine leiomyosarcoma and lung metastasis. This is a rare case of uterine leiomyosarcoma associated with an acute respiratory emergency as a main clinical feature.
\end{abstract}

Keywords: Uterine Leiomyosarcoma; Lung Metastasis; Metastasectomy; Acute Respiratory Distress; Uterine Tumor

\section{Introduction}

Uterine leiomyosarcoma is an uncommon and aggressive malignancy of the myometrial smooth muscle with high rates of local recurrence and metastasis [1-3]. The tumor usually metastasizes mainly hematogenously to the lungs, but it can also disseminate to peritoneal cavity and retroperitoneum [4-6], followed by the brain, bone and skeletal muscle. The time interval to the detection of metastasis is generally short, although there are some longer-period reports [7-10]. We encountered a patient with uterine leiomyosarcoma associated with sudden onset of acute respiratory distress due to a giant pulmonary lesion.

\section{Case Report}

A 47-year-old Japanese woman presented with sudden onset of progressive shortness of breath and dyspnea. Her clinical data reported giant uterine tumor $(20 \mathrm{~cm}$-sized) highly suspicious for 'leiomyoma' (Figure 1) at previous physician 5 years before her presentation, but she had not undergone a hysterectomy. Emergent contrast-enhanced CT showed a huge solid mass with smooth borders in the mediastinum and right pulmonary atelectasis (Figure 2). The lesion was pressure on the trachea; there was a risk of suffocation. She was then submitted to emergency surgery to remove of the mediastinal tumor. The mass could be separated from the surrounding tissues and was entirely removed. A rapidly favorable course led to laparotomy 5 months after thoracotomy for the purpose of uterine mass removal. Its complete removal and bilateral salpingo-oophorectomy were possible after ligating the uterine artery. The pelvic cavity was thoroughly examined, and no evidence of invasion metastasis was noted. The final histopathologic evaluation of uterine tumor revealed low-grade pleomorphic leiomyosarcoma, a diagnosis consistent with that for 
the lung lesion. Following surgical intervention, an adjuvant chemotherapy with adriamycin is planned to the patient.

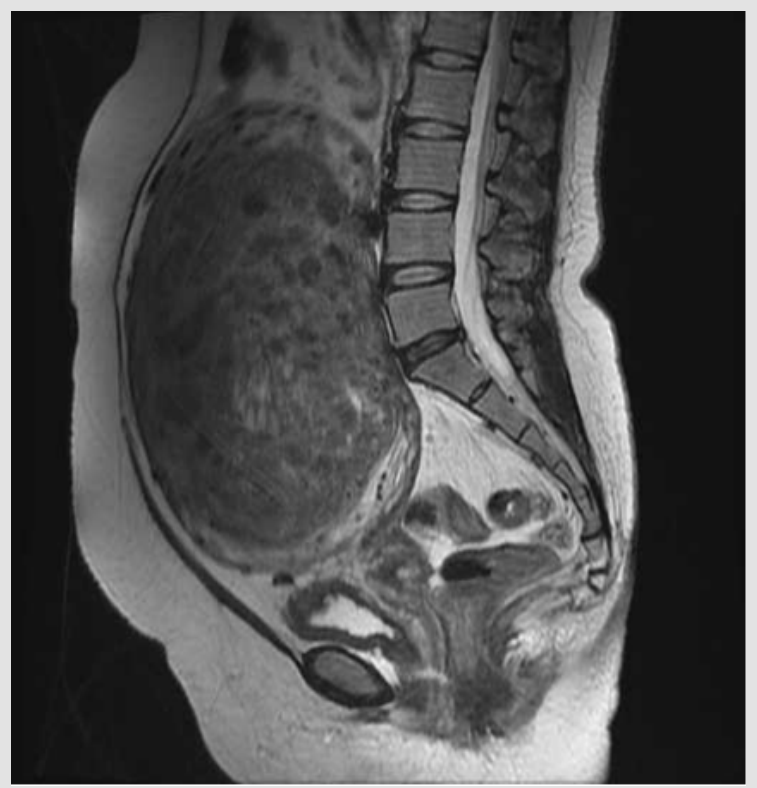

Figure 1: Sagittal T2-weighted MR image at previous physician 5 years before her initial presentation. A $20 \mathrm{~cm}$-sized heterogenous uterine mass was suspicious for 'leiomyoma'.
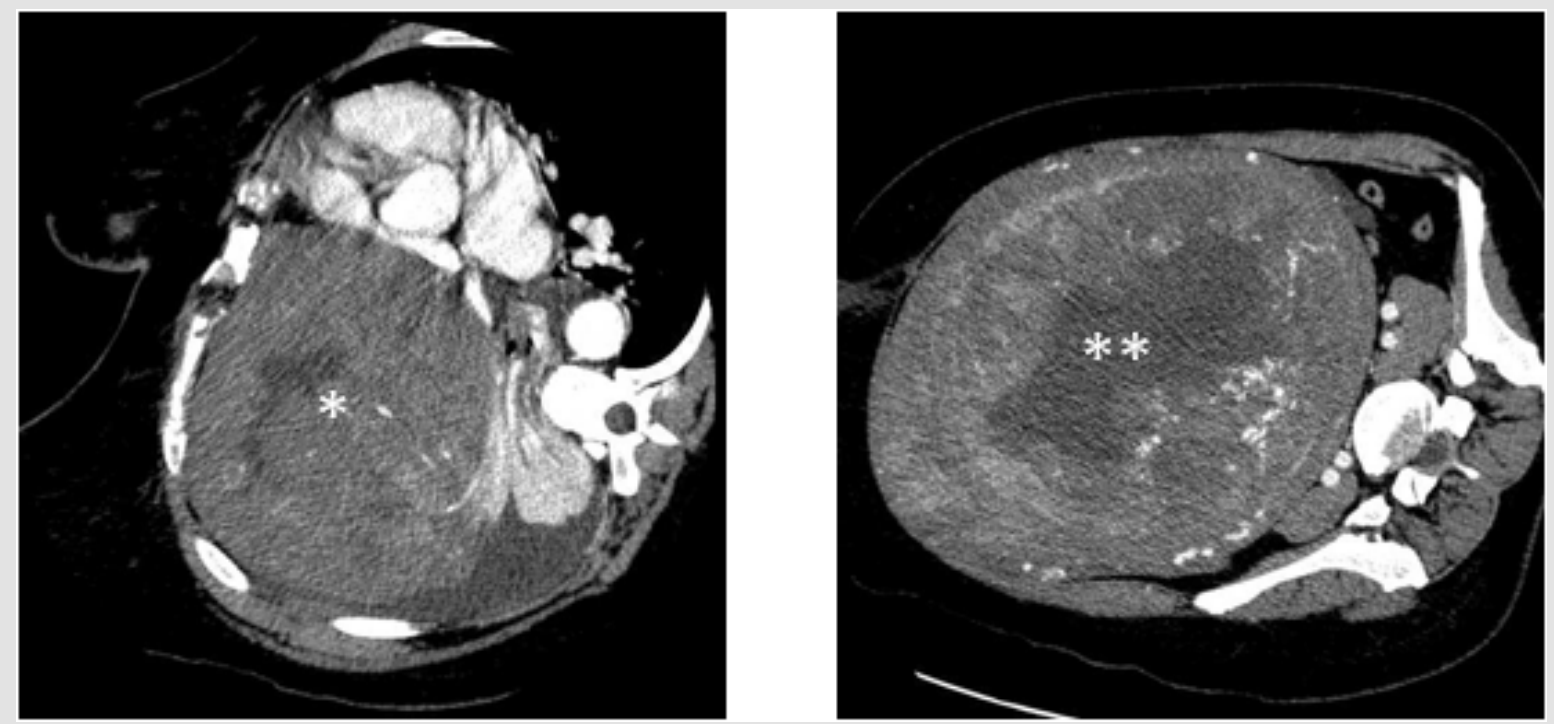

Figure 2: Axial contrast-enhanced thoracic (left) and abdominal (right) CT images showing the heterogenous masses with $15 \mathrm{~cm}$ in greatest dimension in right mediastinum $\left(^{*}\right)$ and $20 \mathrm{~cm}$ in lower abdomen $\left(^{* *}\right)$. They seemed to have similar content intensity and relatively well-defined limits. The patient could not bring in the supine position because of respiratory dyspnea and pain.

\section{Comments}

Fortunately, it was possible to review the MRI 5 years before her first presentation and no lung lesion was detected. Base on the past medical history and histological similarity, she was diagnosed with uterine leiomyosarcoma and lung metastasis. The hypothesis of a lung metastasis was considered during recent years.

Lung metastasectomy is a feasible and acceptable treatment in certain patients with one or two lung metastatic lesions [4-
6]. We described an interesting case of uterine leiomyosarcoma associated with an acute respiratory emergency as a main clinical feature. Although the patient is still under intensive care, the dismal prognosis of uterine leiomyosarcoma, in particular with distant metastasis, prompted us to report the adequate metastasectomy followed with adjuvant chemotherapy. This study may provide new insights into management procedure of highly malignant lesions with distal metastasis. 


\section{Disclosure Statement}

The authors declare no conflict of interests regarding the publication of this report.

\section{References}

1. Roberts ME, Aynardi JT, Chu CS (2018) Uterine leiomyosarcoma: a review of the literature and update on management options. Gynecol Oncol 151(3): 562-572.

2. Cui RR, Wright JD, Hou JY (2017) Uterine leiomyosarcoma: a review of recent advances in molecular biology, clinical management and outcome. BJOG 124(7): 1028-1037.

3. Juhasz Böss I, Gabriel L, Bohle RM, Horn LC, Solomayer EF, et al. (2018) Uterine Leiomyosarcoma. Oncol Res Treat 41(11): 680-686.

4. Paik ES, Yoon A, Lee YY, Kim TJ, Lee JW, et al. (2015) Pulmonary metastasectomy in uterine malignancy: outcomes and prognostic factors. J Gynecol Oncol 26(4): 270-276.

5. Bartosch C, Afonso M, Pires Luís AS, Galaghar A, Guimarães M, et al. (2017) Distant metastases in uterine leiomyosarcomas: the wide variety

ISSN: 2574-1241

DOI: $10.26717 /$ BJSTR.2020.25.004250

Atsushi Imai. Biomed J Sci \& Tech Res

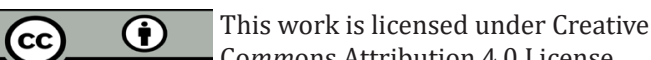

Submission Link: https://biomedres.us/submit-manuscript.php of body sites and time intervals to metastatic relapse. Int I Gynecol Pathol 36(1): 31-41.

6. Anraku M, Yokoi K, Nakagawa K, Fujisawa T, Nakajima J, et al. (2004) Pulmonary metastases from uterine malignancies: results of surgical resection in 133 patients. J Thorac Cardiovasc Surg 127(4): 1107-1112.

7. Carreiro A, Frias L, Miguel A, Rocha M, Carneiro V, et al. (2014) Unusual late lung metastasis from leiomyosarcoma of the uterus. Rev Port Pneumol 20(4): 223-224.

8. Mizuno T, Imai A, Hirose Y (2007) Skeletal muscle metastatic and pelvic leiomyosarcomas following hysterectomy. Int J Gynaecol Obstet 96(1): $49-50$

9. Guazzaroni M, Tosti D, Rascioni M, Mataloni M, Citraro D, et al. (2014) Lung metastasis after an eighteen-year-long disease-free period since uterine leiomyosarcoma diagnosis. Case Rep Oncol Med 2014: 961675.

10. Strickland KC, Nucci MR, Esselen KM, Muto MG, Chopra S, et al. (2016) Solitary fibrous tumor of the uterus presenting with lung metastases: a case report. Int J Gynecol Pathol 35(1): 25-29.

$\begin{array}{ll}\text { BIOMEDICAL } & \text { Assets of Publishing with us } \\ \text { RESEARCHES } & \text { - Global archiving of articles } \\ \text { - Immediate, unrestricted online access }\end{array}$

